\title{
Intracranial Laceration Related to Birth
}

National Cancer Institute

\section{Source}

National Cancer Institute. Intracranial Laceration Related to Birth. NCI Thesaurus. Code C116908.

Tearing of the cerebral or cerebellar parenchyma or vessels of a newborn infant due to forces occurring during labor and delivery. 